and the speech was stammering, and had been so since the fit. There was no loss of power or sensibility of the skin in any part excepting that the left side of the face was wanting in expression. He soon ceased to attend.

Upper Brook-street, W., 1870.

\section{IDIOPATHIC GANGRENE OF THE FOUR EXTREMITIES, NOSE, AND EARS.}

AMPUTATION OF THE EXTREMITIES; RECOVERY.

BY JOHN R. BEGG,

SURGRON TO THE DUNDEN ROTAL INFTRMARY, ETC.

Mrs. Euizabeth R-, aged twenty-one, was admitted into the Dundee Royal Infirmary on the 25th May, 1869. She had been delivered of a healthy male child on the 24th March previons. She stated that the labour was a protracted one; that afterwards she did not partake of nourishment proper to one in her condition, and that she therefore remained in a weakly state for some time. She had, however, quite recovered from her confinement, and was following her household duties, when, one day, a little over a fortnight previous to her admission to the infirmary, she was seized with an itchy sensation in both her hands; this was followed by slight pain, and at the same time she noticed the tips of the small and ring fingers of the left hand become of a blue colour. Previous to this, however, there had appeared a blue spot on the tip of the nose; and shortly after the left hand had been attacked with the blueness, the left foot exbibited a similar appearance; then the right hand, the right foot, and finally the lobules of the ears: the blueness always commencing at the tips of the fingers and toes, and gradually ascending. She then experienced a feeling of numbness in the parts, and latterly pain whenever she made any movement.

Previous to this illness the patient had always enjoyed the best of health. Her medical attendant stated that her labour, although lingering, was a natural one; that she got abont sixty-five grains of ergot in infusion in two doses; and that she marle a fair recovery. Mrs. R- stated that for years she had suffered from coldness of her extremities, more especially her hands, and that even in the hottest days of suminer. Her husband remarked the extreme coldness of her fingers, hands, and feet, and often applied remedies to warm them.

On admission, the diseased parts were found, on careful examination, to be in the following condition:-1st. On the tip of the nose there was an irregularly-shaped black patch, of about the size of a fourpenny-piece, hard and dry. 2nd. The fingers of the right hand were flexed, black, withered, and devoid of feeling as far as the middle joints. On the dorsal or posterior aspect of the hand, and extending for about two and a half inches above the wrist, the integuments were of a purple colour, mottled here and there with shades of a darker hue; the forearm above the wrist was of sunoky colour; the corresponding part on the palmar surface of the forearm, where it extended for the same distance, was of a reddish tint. 3rd. The left hand was dark in colour; the fingers flexed and withered, and devoid of sensibility up to the middle joints. The blackness in this hand extended from an inch and a half to two inches above the metacarpo-phalangeal joint, where there appeared to be an irregular line of demarcation forming; and towards that point it was of a lighter or reddish colour. 4th. The left foot was for the most part of a light-red hue, with a slight intermixture on the dorsum of a darker colour. It reached from about three to three and a balf inches above the ankle. joint, on the anterior surface of the leg, where the line of demarcation was forming. Some large bullæ bad formed. The toes were black, withered, and devoid of feeling up to the middle joints. 'The integument on the plantar aspect of the foot was of a dark colour. 5th. The rirbt foot was of a dark-red hue, mingled here and there with shades of a darker cast. The toes were black, and withered up to the middle joints. The discoloration of the skin extended about three and a half inches above the ankle-joint, where a line of demarcation was forming. Some bullæ bad formed near the line of demarcation. The sole of the foot was of a dark colour. The whole of the extremities were cold to the feel as far as the discoloration extended.

The patient was ordered a lileral diet, with wine, brandy, and beer; a morphia draught and a dose of castor oil when necessary.

June 14th.- Up to this date little change has taken place in the patient's condition. The pulse kept at about 120 . The line of demarcation is now well formed; suppuration has commenced in the lower extremities; tendo Achillis slightly exposed in left leg. The gangrene in the lower extremities is of the moist or humid kind; in the upper, the dry or mummified. Urine normal. Has been taking her food tolerably well ; relishes her wine, brandy, and beer.

17th.-This morning, at 10.30 , the patient was placed under the influence of chloroform, and amputation performed in both legs, about their middle. In either case short anterior and long posterior flaps were made. The usual number of arteries required to he ]jgatured. Very little blood was lost during the operitions. The anterior tibial arteries in both amputated extremities were found to be pervious as far as they could be traced.

July 2nd.- Up to this date the patient has progressed favourably, with scarcely a bad symptom. The tip of the nose was removed yesterday, and, some days before, portions of the lobules of the ears. Pulse normal; tongue clean; appetite good; sleeps well; very cheerful; stumps looking well, nearly whole. The left band is much the same; in the right the line of demarcation is well defined. and suppuration has taken place between the dead and living parts.

9th.-At 10.30 A.M. the patient was chloroformed, and both upper extremities were amputated: the right about three inches above the wrist; the left at the wrist, removing the articular ends of the radius and ulna. No blood was lost beyond what it was impossible to prevent. Patient. stood the operations well.

Oct. 1st.-Since the upper extremities were amputated patient has never had a bad symptom; her health and spirits are now all that could be desired. The stumps of both upper and lower extremities are perfectly sound, and able to bear a great amount of pressure. She has been out of bed daily for some time, and has been amusing herself by writing with a pen and holder secured to her right arm stump. She began by writing on slips of paper a few proper names, but she is now able by this means to keep up a correspondence with her friends. Her writing is marvellous.

16th. - The patient left the infirmary to-day for London, to be under the charge of Mr. Heather Bigg.

Fortunately, cases of idiopathic gangrene, such as the one now described, are of rare occurrence in this country, and few of them are to be found in the records of surgery. Mrs. R-'s case is therefore one of the first importance, both for its bistory and its termination. The gangrene commenced about forty-six days after accouchement, and forty days after the commencement of the gangrene both legs were amputated. Twenty-two days after the first double amputation, the second double operation was performed. She made a most wonderful recovery, and left the infirmary after a residence of one hundred and forty-three days, or about four and a balf months.

Amputation in gangrene, whether traumatic or idiopathic, has been, and is still, a question on which there are diversities of opinion among surgeous; but I think all surgeons are now agreed that amputation should never be performed in idiopathic gangrene until the line of demarcation has been sufficiently well established. But although all are agreed on that point, there are still differences of opinion as to how the operation should be performed. If we consult the early writers on the subject, we find that they left the gangrenous extremities to be amputated by nature, merely removing the mortified parts at the articulation nearest the line of demareation. Modern surgeons, for the most part, advise little interference-waiting until the gangrenous parts are nearly detacbed, then dissecting the granulating parts a little upwards, and dividing the bone with a saw. Sir W. Fergusson, however, sass there cannot be a doubt that the surgeon is justified in many cases in performing amputation.

After the line of demareation was sufficiently well formed, and ulceration had extended so as to expose the deep tissues of the legs, there was a large amount of disacreeable fetid discharge, besides the offensive putrid feet and legs, which 
were evidently producing and keeping up much constitutional disturbance. As the circulation in the popliteal arteries was normal, I thought that, if my patient had a chance of recovery at, all, that chance would be affurded by amputation. Fad the amputation been left to nature, I have no doubt the termination of the case would have been diffrent, is there was not sufficient strength of system to undergo the exhanstive process of nlceration and suppuration necresa $y$ for the separation of the mortified parts; an 1, supposing that nature had been able to perform the ampu ativus, there would have been left perfectly useless stumps. Instures are not wanting where the gangrenous extremities have been left to be amputated by nature, in which the patients have afterwards submitted to amputation in order to obtain more useful stumps. Assuredjy I did what was best for the interest of my patient when I removed the offensive sphacelated parts, and affurded sound and useful stumps for the adaptation of artificial extremities.

'The treatment of the case was directed to assuage pain, lessen nervons irritability, and support the system against the debilitating effects that must necessarily accompany the process of ulceration and suppuration. The strength of the patient was kept up by a generous diet, and a liberal allowance of stimulants.

One of the most important inquiries in this case is as to what caused this extensive and unusual disorganisation, and to which of the recounised causes of idiopathic gangrene it could be assigned. It will only be necessary to refer to those causes which have a direct bearing on this case; and I think the first that naturally presents itself is, ergotism. All the profe-sional gentlemen who saw this case after the disease had been sufficiently well established said : "Why, this must be a case of erontismal gangrene"; and although it is a rare disease in this country, yet instances are not wanting of gangrene following the use of bad black wheat or rye.

When gangrene arises from this canse it does not usually occur in isolited cases, but generally attacks whole families, sometimes whole districts, as is graphically described by continental writers. Dr. Wollaston describes the disease as occurring in a whole family in Suffolk afier using bread ma ie from un wholesome wheat. It will be interesting to give the result The father recovered with the loss of two fingers; the mother lost the right foot at the ankle, and the left leg below the knee, the fingers of both hands contracted and almost lost their sensibility; three of the family lost both legs below the knee-one of them died; one lost both feet at the ankle-joints; another, one foot and two toes; and un infant died. ("Philosophical Transactions," 1762)

Mr. Camps gives a case of supposed ergotism. The mun recovered with the luss of both feet a little above the ankles, both thumbs and forefingers at the middle of their first phalanges, and the remaining fingers at the first and second pbalanges. (British and Foreign Mredico-Chirurgical Review, July, 1855)

In Mrs $R$ - 's case we have all the well-maxked symptoms and results of ergotism. The history of her case, however, nt once precludes the idea of her disease originating from that cause; as, bad such been the case, otbers who were subjected to the same mode of living would have been more or less affected in a similar way. True it is that, during ber labour, she had administered to her about sixtyfive grains of ergot in iufusion; but $I$ do not think that it had the least influence in producing the remarkable and un. usual gangrene that shortly afterwards followed. Were such the case how often would we bave gangrene following the use of eront in midwifery practice. I might safely say that it is used by medical practitioners all over the world in a large propurtion of their midwifery cases, and with no bad results following.

Numerous cases are on record of gangrene from embolism; but these were wholly confined to one of the upper or lower extremities.

In Irs. $\mathrm{R}$ - 's case there was certainly no ossification of the arteries. There was no arteritis or venous obstruction, no beart-disease nor diminution of the heart's action, and no want of nervous energy; for Mrs. R- had a wellregulated and active nervous ssstem. Neither can the cause be assigned to, or connected with, a cachectic or broken down state of the constitution; as, had such been the case, there would have been little or no chance of her. recovery.
There is one remarkable and striking feature in the history of this case which forns a most important element in defermining the cause of the disease, and that is, that she suffered for years from extr me coldness of the extremities. I must confess that, until this feature in the case was brought accidentally to light, the cause of the disease was a mere matter of conjecture, and shrouded in the greatest obscurity; but the accidertal discovery of the long-continued cold extrenities at once gave the clew to what must be accepted as the true expla ation of the origin of this remarkable gangrene. The colduess of the extremities must bave arisen from a weak and insufficient capillary circulation, which mus have existed for a considerable time; and, bearing this in mind, the true cause of the disense will be easily ascertained by shortly reviewing the patient's previous bistory.

Mrs. R-, prior to her marriage, was a servant in the family of a baronet, where she was accustomed to good living. From this situation she was narried to a working gardener; his means being limited, her mode of living would necesarily be very different from that to which she hat hitberto been accustomed. In the ordinary course of events she gave birth to a bealthy living child; and here is an important crisis in the case: she says that "afterwards (after the birth) she did not partake of pruper nourisbment required for one in her condition, and therefore remained in a weakly state, but was able to resume her domestic duties."

There can be no douht that in the abnormal coldness of the extremities there lurked the latent predisposition to the disease, and that there was only wanting a particular state of constitution calculated to promote its development,- -avd that state was doubtless produced by her different mode of living subsequent to marriage, combined with the debilitating influence of child-bearing. 'laking these circumstances into account, it seems evident that, owing to the organic changes in the capillaries of the extremities, the parts did not receive an amount of nutrition sufficient for the sustenance of life. In this form of gangrene arising from organic changes in the capillaries we would nuturally expect to find the dry or mummified; but it is remarkableand what, $I$ believe, has not previously been fonnd or recorded in any other case-that there were the two well. marked varieties-in the lower extremities the moist or humid, and in the upper the dry or mummified.

That the same cause was at work in producing both varieties of gangrene there can be no doubt. Contrary to what was expected, in tracing the tikial arteries in the mortified parts of the lower extremities after amputation, they were found pervious; but, from the advanced state of the gangrene, it was impossible to say in what enndition they had been previously. In the upper extremities the state of the vessels could not be ascertained, as the parts were hard and dry.

Amputation has often been performed in cases of idiopathic gangrene where no bloodvessels required ligatures; but in Mrs. R_-'s case, both in the upper and lower extremities, the usual number of vessels required to be ligatured. This fact, taken in connexion with the history of the case, proves quite conclusively that the capillaries were the true and original site of the gangrene. Some few cases are recorded closely resembling Mrs. R_-'s: one by M. Raymonds (Year-book of Medicine and Surgery, 1862); and another by Dr. Henry of Pbiladelphia (Brit. and For. Med.Chir. Rev., July, 1356); hoth cases ended fatally.

The following is a brief summary of the chief points of interest in Mrs. $R$ —'s case :-

1. Mrs. R- was only twenty-one years of age.

2. Idiopathic gangrene of the four extremities, nose, and ears is of rare occurrence in this country; and this is the only case on record which has been known to recover.

3. The treatment of the case was mainly directed to supporting the system by nutritious diet and stinulants.

4. The two varieties of gangrene occurring in the same case must be extremely rare, as I do not find mention made of such a case by any of the must eminent surgical writers.

5. Two double amputations were performed within twentytwo days.

6. The usual number of arteries were required to be ligatured in all the operations. 
7. This is the only case where the four extremities bave been successfilly amputated in idiopathic gangrene.

8. The cause of the disease was organic changes in the capillaries.

The accompanying sketch was taken immediately before Mrs. R- left the infirmary. It represents faithfully the condition of ber amputated extremities. It will be seen that the ears suffered but slightly; and that the nose, although it lost a considerable portion, recovered without leaving much deformity.

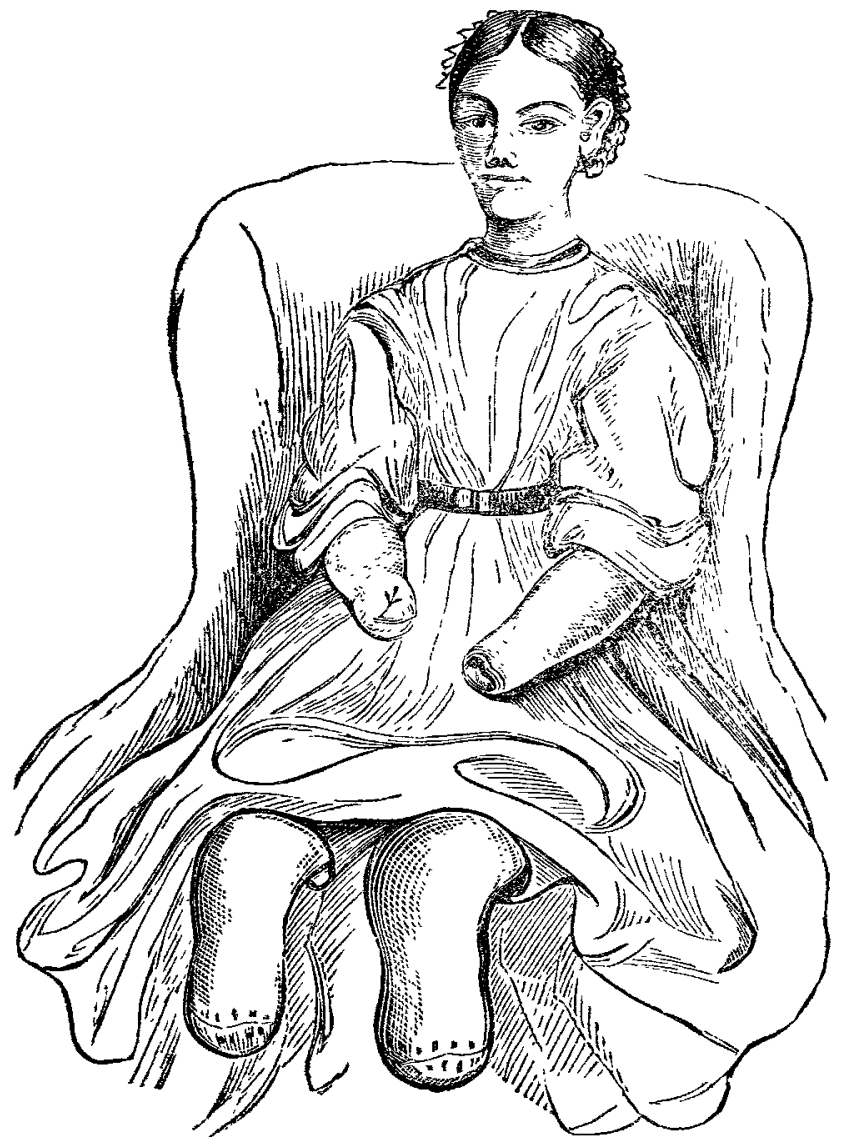

My thanks are due to Dr. White, the resident surgeon in charge of the case, for the care and attention he bestowed in attending Mrs. R-, and in carrying out the prescribed treatment.

On leaving the infirmary, Mrs. R- went direct to Iondon, where she had four artificial extremities supplied by Mr. Heather Bigg. By means of these ingenious appliances she is able to walk, use a knife and fork, knit, crotchet, and perform the minutest manipulations, even to the picking up of a pin. For a description of their mechanical construction, see THE LANCET of Feb. 15th, 1870.

Mrs. R- is now living in Devonshire, and from a letter I had, written by herself a few days ago, I learn that she is in the enjoyment of excellent health and buoyant spirits. Dundee, August, 1870 .

\section{CASE OF TRAUMATIC TFTANUS, TREATED} BY BELLADONNA, QUINA, AND PURGATIVES; RECOVERY.

\section{BY HENRY COOPER ROSE, M.D.}

H. R-, aged fifteen, apparently in fair health, came ander my care on March 31st, 1870, with the following history:- About ten days before the above date he had scratched his leg ratber deeply with a nail while at play. The wound was dressed with wet lint, and seemed to be doing so well that no notice was taken of it after the first two or three days. A few days before I saw him the wound had become worse and painful, but he said nothing about it until the eveniug of March $29 t h$, when he complained of feeling very unwell, and of a stiffness about the angles of the javs. The wound appeared inflamed, and was again dressed with wet lint, and he was kept quiet.
At 8 P.M. of March 31 st I was sent for. I found the lad in bed, with an anxious countenance, hot skin, quick pulse, dilated nostrils, great stiffness about the jaws (he being only able to very partially open the mouth), and the wound in the leg very deep, leading down to the periosteum, and situate on the outer side of the right leg, about six inches above the outer malleolus The leg looked inflamed around, and the wound gave exit to a thin, sanguineous, and somewhat offensive discharge. I immediately entirely destroyed the surface of the wound by a most thorough application of the solid nitrate of silver, ordered a linseed-meal poultice to be applied, and (enjoining absolute quietude) prescribed the following:-Calomel, six grains; jalap powder, one scruple: to be taken immediately, and to be followed by enemata of sulphate of magnesia until copious evacuation resulted. Tincture of belladonna, twenty minims; tincture of quina, one drachm; sulphate of quina, one grain: to be taken every four hours. Extract of belladonna, one ounce; solution of ammonia (strong), half a drachm : mix: a portion to be rubbed into the whole course of the spine three times a day. Jalap powder, ten grains; calomel, one grain : to be taken every four hours.

April 1st.-Through the night he had frequent spasms, which threw him into various painful contortions, opisthotonos occurring at intervals; jaws firmly closed. The bowels had not acted well. Continue powder, medicine, and enemata. In the evening I found the symptoms somewhat relieved; the tetanic spasms were not so frequent, the bowels had acted very copiously, and he had been able to swallow some beef-tea and wine when poured between the cheek and teeth.

2nd.-Symptoms much the same. He had had sleep several times of short duration. Pulse 120; skin moist. The slough produced by the nitrate of silver had come away. The wound was filled up with cotton wool, saturated with carbolic-acid lotion (two drachms to six ounces), and covered with a linseed poultice. Mixture continued.

3rd.-11 A.M.: I found him greatly distressed, terrible spasms coming on at intervals of three minutes, accompanied by loud screams. Pulse 130. He had had a quiet night, sleeping for two hours at a time; and the change bad taken place without any apparent, cause about an hour hefore my arrival. Abdominal musclis very tense and painful. Ordered turpentine stupes to the abdomen; calomeland-jalap purge, and enemata of sulplate of magnesia; wine and beef-tea.-At 4 P.M. I visited him again, accompanied by Mr. Shaw, of Hampstead, with the intention of administerino chloroforn; but I found him quieter, the spasms less frequent, and not nearly so violent. The bowels had been freely relieved. I withbeld the chloroform. To continue the mixture; discontinue the powders.

4th.-Morning: Had had a quiet night, sleeping at intervals for the space of an bour or two. Was cheerful, and talked rationally. Pulse 100 . He had taken nourishment plentifully-milk (thickened with farina), beef-tea, and $80 z$. of wine in twenty four hours. Since the previous evening the sprsms had been very few and slight.-Evening: Pulse 100. Spasms almost absent until 7 P.M., when they began a,grin to be troublesome. Ordered another purge, and the mixture to be continued. The jaws could be opened about half an inch. The pupils were largely dilated, and he complained of occasional blindness. He urgently requested that the belladonna might be rubbed into the sides of the neck and angles of his jaws, declaring that he felt relief after each application of it to the spine. This was accordingly done, and the mixture was ordered to be taken every six hours.

5th.-Considerahle improvement had taken place in every respect. He had slept well, was cheerful, the bowels had been freely relifved, and the movement of the jaws was much greater. There had been no spasms since last evening, and his general aspect was improved.

6th.-Had passed an excellent night; no spasms. The jaws, though still feeling stiff, were freely movable, and he asked for, and enjoyed, some thin bread-and-jam. The wound in bis leg was granulating fast, and was healthy in character; and from this date the patient made an uninterrupted recovery. Mr. Shaw, of Hampstead, frequently saw the patient with me.

Hampstead, August, 1970 . 